\title{
Социальная мобильность в приграничье: взгляд молодежи
}

Традиционно под социальной мобильностью в социологии было принято понимать перемещение отдельных лиц или групп в рамках занимаемых ими социальных позиций, чаще всего подразумевая смену занимаемых социальных страт, рост благосостояния и социальных статусов. Социальная мобильность, по мнению П. Сорокина, это "любой переход индивида или социального объекта (ценности), то есть всего того, что создано или модифицировано человеческой деятельностью, из одной социальной позиции в другую" [14, c. 292]. Такое движение к успеху обеспечивается разными способами, через получение образования, усердный труд, наличие особых способностей, таланта, использование социальных связей и т.д., но всегда подразумевает наличие социальной активности индивида.

Мобильность - это доминантная модальность социального бытия, атрибутивный признак практически всех современных социальных практик [8, c. 37]. Понятие "мобильность" уходит от чисто социологической трактовки "мобильность-адаптивность-успешность", предполагающей переход из социальной страты в другую, к осознанию масштабности и скорости изменений и трансформаций, характерных для современного общества, как технологическое ускорение всех социальных коммуникаций и действий [9]. Что предполагает наличие установки личности на изменения с помощью современных технологий и способности к ускоренной коммуникационной интеракции. Э. Берджес указывает, что "мобильность естественным образом заключает в себе изменение, новый опыт, стимуляцию" [3, с. 30] и сама выступает маркером социальных трансформаций.

Соџиально активная личность или актор, то есть человек принимающий решения самостоятельно и действующий согласно собственным решениям, потребностям и ценностям, - это основа современной социальной мобильности в любом ее проявлении. Актор, по мнению А. Турена, это человек действующий, который придает общественную фрорму значимым для него ориентациям [15], это индивид, обладающий активным восприятием мира, также мировоззрением, сконструированным под структурным давлением [4]. Э. Гидденс уточняет, что социальный агент - это деятель, социально-активная личность, главным качеством которой является рефлексивность [5].

Мобильность во многом выступает атрибутом эпохи глобализации и информационного общества. Дж. Урри также отмечает, что мобильность в современном обществе связана не столько с перемещением от одной социальной позиции к другой вверх или вниз, а больше с горизонтальными перемещениями, соединяющими движения индивидов и групп в единую социальную сеть, создающую сетевой капитал, путем укрепления социальных связей [16]. Вся социальная жизнь происходит через взаимосвязанные пересекающиеся процессы, включающие в себя различные типы движения. Мобильность, по его мнению, может подорвать социетальные границы, делая их проницаемыми и делая социальное мобильным. В данном разрезе особое значение приобретает

(C) Костина Е. Ю., Орлова Н. А., 2020

КОСТИНА Елена Юрьевна, канд. социол. наук, директор департамента социальных наук Дальневосточного федерального университета (2. Владивосток). E-mail: kostinaeu2000@ mail.ru

ОРЛОВА Надежда Александровна, канд. социол. наук, доцент департамента социальных наук Дальневосточного федерального университета (2. Владивосток). E-mail: nadinorlo@yandex. $\mathrm{ru}$

Исследование выполнено при финансовой поддержке РФФИ и ЭИСИ в рамках научного проекта № 20-011-31491 
социальная активность молодежи, которая всегда выступает источником изменений и инноваций, так как ее деятельность ориентирована на будущее, на преобразование существующей социальной реальности.

Молодежь традиционно рассматривается как наиболее социально активная возрастная группа, которая занимает основное место в общественном воспроизводстве культурных, социальных, политических, экономических и общественных практик. Присущая молодежи склонность к инноващиям и готовность к изменениям порождает амбивалентное отношение к этой демографической группе, когда, с одной стороны, "на молодежь смотрят с надеждой, с другой - с тревогой и завистью" [11, с. 67]. В обществе всегда было понимание, что именно молодые люди являются носителями особых сощиальных функций, которые не может взять на себя никакая иная социальная группа. Ведь молодежь не просто "наследует" достигнутый уровень и структуру развития общества, но и формирует уже сейчас его будущий вид, такой странный симбиоз преемственности, воспроизводства и трансформации. Присущая молодежи инновационность определяет ее особое "предназначение" выступать пионерами общественных преобразований.

Лев Гудков из "Левада-центра" убеждён, что сегодняшняя молодежь отличается в целом невысокими запросами, в основном прагматическими, хочет большую зарплату, быструю карьеру, ориентирована на определенный уровень потребления, к сожалению, она также ориентирована на высокий уровень потребления вне зависимости от того, как это происходит и какими средствами обеспечивается [7]. Российская молодежь отличается, по мнению Н.Л. Антоновой, практичностью, самостоятельностью и высокой мобильностью [2, с. 277]. Получение образования, выбор места работы, смены места жительства - всё это молодые люди выбирают исходя из имеющихся у них жизненных планов и целей, потребностей и интересов.

Основываясь на концепция эндогенного роста П. Ромера и Р. Лукаса, которая фрормализует связь между механизмами экономического роста и процессами получения и накопления нового знания, материализуемого затем в технологических нововведениях, необходимо обратить внимание на то, что ключевым фрактором роста экономики любого региона выступает привлечение знаний и человеческого капитала, то есть людей как носителей данно го знания, навыков и опыта. Человеческий капитал - это совокупность всех приоритетных знаний, умений, навыков, опыта и здоровья, которые человек использует в своей профессиональной деятельности. Сегодня сложно представить, что в современной экономике можно быть нужным и востребованным без специального образования, так как работы для выполнения, которых не требуется специальное обучение или механизируют, или отдают на откуп трудовым мигрантам.

Работающие в настоящее время люди вынуждены постоянно повышать профессиональную квалифрикацию и овладевать новыми профеессиональными умениями и навыками, что диктуется требованиями современного рынка труда и экономики. Известно, что современные прогнозы в области профессий, которые будут востребованы в экономике в ближайшее время, говорят о том, что современные студенты будут вынуждены за время своей карьеры сменить до трех профрессий, причем речь в данном вопросе идет не об очередном повышении квалификации, а о кардинальной смене сферы деятельности. Также расширяется требование к базовым умениям и навыкам, которыми должны владеть специалисты будущего, так, например, считается, что владение английским языком и навыками программирования станет обязательным для многих напрямую не связанных с этим профессий.

Традиционная, к сожалению, ситуация исхода трудоспособного населения с регионов Сибири и Дальнего Востока за более качественной и устроенной жизнью в европейские регионы РФ и за рубеж, подрывает экономический и социальный потенциал данного региона. Причем при острой необходимости ухода в данных регионах от сырьевого типа промышленности возникает потребность не столько в людях/кадрах, сколько речь идет о человеческом капитале, который сможет развивать инновационную высокотехнологическую промышленность. А данную проблему не решить просто разовыми инвестициями или выплатой "подъемных" приезжающим из других регионов, на что нацелено ряд государственных программ, ориентированных на привлечение 
и закрепление населения на Дальнем Востоке [17]. По мнению И.П. Глазыриной и Л.М. Фалейчик, "когда ставится задача сохранения человеческого капитала, речь идет о спросе на качество жизни и предложении этого качества в условиях конкретной территории" [6, с. 7].

Территории Дальнего Востока России имеют наземную границу с Китаем, а также водную с Южной Кореей, Японией, США и Канадой, все эти страны имеют современную промышленность инновационного типа, а также обеспечивают более высокое качество жизни своему населению. И если не стремиться к развитию такого же типа производства на данной части российской территории, то избежать превращения ее в сырьевой придаток азиатский стран станет невозможным. А так как сырьевая экономика всегда менее требовательна к качеству человеческого капитала, то в регион если и будет приезжать на заработки, то это будут люди, чьих навыков будет недостаточно для изменения сложившейся ситуации. Только путем привлечения и закрепления в регионе достаточного по количеству и качеству человеческого капитала можно изменить структуру и модернизировать региональную экономику. И надо отметить, что государство понимает, что именно молодежь должна стать основой данного инновационного капитала. Так, в Распоряжение Правительства РФ "Об утверждении Основ государственной молодежной политики Российской Федерации на период до 2025 года" указывается: "стратегические преимущества будут у тех государств, которые смогут эфрфективно и продуктивно использовать инновационный потенциал развития, основным носителем которого является молодежь" [12].

Осуществить анализ вопросов, обозначенных в рамках очерченной тематики, позволяют результаты, полученные авторами в ходе проведенного в ноябре-декабре 2019 г. эмпирического исследования, которое было направлено на изучение формирования профессиональных намерений студентов на различных этапах профессиональной подготовки и их миграционных стратегий ${ }^{1}$.

Поскольку человеческий капитал включает в себя совокупность всех приоритетных знаний, умений, навыков, которые фрормируются в процессе получения образования, становления молодого специалиста, немаловажным является вопрос, как изначально происходит выбор будущей профессии. Так, результаты опроса показали, что основными параметрами такого выбора для респондентов явились "любовь к профессии" (34,2\%) и "способности к данному виду профессиональной деятельности" (31,6\%). Часть студентов предпочли дать свои ответы на заданный вопрос, из них превалировали следующие: "интерес", "желание", "по результатам ЕГЭ", "куда прошел". В целом полученные данные показывают, что при выборе студенты в менышей степени были ориентированы на высокие доходы, коммерческие успехи (4,8\%), а скорее основывались на согласовании своих представлений о будущей сфере деятельности и оценках своих способностей и возможностей реализоваться в данной сорере. В контексте исследования данной проблемы, на наш взгляд, немаловажно было выяснить, какие цели в жизни современная молодежь ставит перед собой, как бы они хотели прожить свою жизнь; ведь поставленные цели определяют жизненные стратегии, инструменты их достижения, в том числе и процессы мобильности и возможности социального перемещения личности в будущем. Наиболее часто респонденты выбирали следующие позиции: "добиться высокого уровня благополучия" $(37,2 \%)$ и "жить спокойно, работая и заботясь о своей семье", менее всего - "жить беззаботно, не особо задумываясь о будущем". То есть респонденты указывают на наличие высокого качества жизни в месте постоянного проживания, то есть созданных в обществе условий, позволяющих не просто удовлетворять свои потребности и интересы, а создающих условия для эффрективной жизнедеятельности во всех сфрерах.

При ответе на вопрос "Как бы Вы оценили возможности для профессиональной и творческой самореализации, предоставляемые сегодня молодым людям в Приморском крае?" 9,9\% респондентов выбрали вариант - "отлично, сегодня есть все возможности для полноценного, комплексного развития

1 Объект исследования - студенты 1 и 4 курса всех направлений обучения Школы искусств и гуманитарных наук Дальневосточного федерального университета. Тип выборки - сплошная. Выборочную совокупность составили 374 респондента 
молодых людей"; 34,8\% - "хорошо, молодые люди имеют возможность получить хороший уровень образования, творчески самореализоваться"; 41,4\% "удовлетворительно, некоторые возможности предоставлены, однако они являются недостаточными"; $12,6 \%$ - "плохо, возможности очень ограничены"; 1,6\% - "крайне плохо, никаких возможностей для получения качественного образования и творческой самореализации на сегодняшний день у молодежи нет". При этом существуют некоторые различия в ответах на данный вопрос у студентов 1 и 4 курса. Так, первокурсники более положительно оценивают возможности профессиональной и творческой реализации в крае (выбирая чаще позиции "отлично" и "хорошо" и реже "плохо") по сравнению с четверокурсниками. Это можно объяснить тем, что студенты первого курса стоят в начале этапа вхождения в профессию, а те студенты, которые находятся "на выходе", строят свои предположения исходя из полученного опыта на практиках и во время подработок во время учебы. При этом значимых различий при выборе ответа "удовлетворительно" не наблюдается. В целом можно сделать вывод, что более половины студентов считают, что реализация их потенциала на территории края в той или иной степени ограничена. Также можно прогнозировать, что данные показатели будут увеличиваться по мере вхождения первокурсников в профрессию.

Возможность трудоустройства является одним из показателей для оценки условий, сложившихся на рынке труда для самореализации молодежи. Так, 46,8\% респондентов считают, что сегодня найти работу "скорее трудно", 11\% - "очень трудно", 18,7\% - "скорее легко", 3,2\% - "очень легко", 20,3\% затруднились ответить на данный вопрос. Опрошенные назвали следующие препятствия для получения работы (наиболее часто встречаемые ответы): "отсутствие опыта" (47,3\%), "отсутствие связей" (17,6\%), "отсутствие рабочих мест" (16\%). Таким образом, полученные результаты показывают присутствие пессимистических настроений среди молодежи в вопросах трудоустройства.

Мнения респондентов о характеристиках представителей молодого поколения, которые уезжают из Приморья разделились. Большинство $(65,2 \%)$ считают, что край покидают "наиболее активные, иниџиативные молодые люди". И лишь 34,2\% полагают, что "уезжают из Приморского края только те, кто не смог найти себе применения". Таким образом, у части опрошенных студентов сформирована установка - именно энергичные, деятельные, нацеленные на результат склонны покидать край. Такая установка может привести к выработки определенных паттернов поведения, направленных на стратегию смены места жительства, в целях реализации своих знаний, умений и навыков в более комфортных условиях, в более приветливой адаптивной среде, что негативно может отразиться на тенденциях развития региона.

Ответы на вопрос, касающийся миграционных ориентаций и установок респондентов, показали их высокий уровень готовности переехать из Приморья. 78,3\% опрошенных хотели бы покинуть край. Выразили желание переехать в другой регион Дальнего Востока 6,5\%, в другой регион Российской Федерации — 50,2\%, в другую страну- 43,3\% (при этом если студенты 4 курса склоны выбирать для переезда другие регионы РФ, то студенты 1 курса зарубежье). Полученные результаты подтверждают тезис о молодежи как достаточно мобильной социальной группе, которая не воспринимает смену места жительства как нечто катастрофическое, фратальное, а, наоборот расценивает это как возможность удовлетворить свои личные и семейные потребности (36,9\% респондентов выбрали именно данную позицию, объясняя свое желание покинуть Приморский край). К сожалению, стоит согласиться, что "мы наблюдаем территориальную мобильность от передерии ... к центру" [11, с. 19], осуществляя такое перемещение, молодежь надеется усилить свой социальный капитал, обогатиться новыми социальными связями, обеспечить себе более высокий и стабильный доход. По мнению Е.М. Авраамовой, только 10\% молодых людей обладают всей совокупностью ресурсов, которые обеспечивают устойчивую занятость молодежи, таких как качественное профессиональное образование, успешность предприятия или организации, где работает молодой человек, и совокупный социальный капитал, которым он обладает [1, c. 130]. Следовательно, до $90 \%$ всей современной российской молодежи может быть заинтересовано в поиске лучшего места работы и жительства. Сложившаяся ситуация с оттоком трудоспособного населения из одних регионов 
в другие приводит к дисбалансу рабочей силы между ними и не позволяет некоторым из них достойно развиваться. Стремление и готовность молодежи покинуть регион косвенным образом характеризует сложившуюся в нем экономическую ситуацию и возможности местного рынка труда удовлетворить запросы молодых.

Кроме этого, достаточно высокий процент желающих в перспективе переехать из Приморского края можно объяснить региональными особенностями, а именно, территориальными, социально-эконмическими и т.д. В частности, связанными с тем, что, как было показано выше, ожидания и оцен ки молодежи условий для возможности их профессиональной и творческой реализации в целом ограничены, а также с тем, что жители приграничных регионов в более значительной степени вовлечены в трудовую, образовательную миграцию. С другой стороны, полученные данные не означают, что все ответившие на данный вопрос положительно, в перспективе реализуют свое желание. Стоит отметить, что намеренье сменить место жительства вовсе не означает обязательную миграцию в ближайшем будущем. Л.Л. Рыбаковский, разводя понятия миграция и мобильность, указывает на то, что миграция определяет фракт свершившегося переселения человека, а мобильность - это подвижность и готовность населения к перемещению [13, с. 90]. Таким образом, мобильность выступает первой стадией миграционного процесса, также показатели мобильности будут выше, чем миграция, так как социальные барьеры различного характера могут препятствовать желаемому движению населения. Такая потенциальная мобильность, то есть ориентация на смену места жительства, выступает, на наш взгляд, индикатором социального и экономического развития регионов. Тем не менее то, что только каждый пятый готов остаться в крае, является достаточно тревожным индикатором. Утечка из региона человеческого капитала, в частности, замена людей с высшим образованием на мигрантов с невысоким образовательным цензом, определяет конкурентоспособность региона и перспективы его дальнейшего развития. Привлечение и сохранение человеческого капитала, как было показано выше, является ключевым фрактором развития любого региона.

В вопросах мобильности очень важна позиция молодежи, так как принимаемые и реализуемые ей миграционные намерения приводят к накоплению/оскудению человеческого потенциала региона, без которого невозможно стабильное экономическое и социальное развитие региона. Особенно чувствительны данные процессы для приграничных регионов, для которых важно сохранение территорий, культуры на фрорпостах своей страны. Ключевое значение приобретает социальная активность молодежи как основного ресурса развития территорий, повышения его конкурентоспособности. Особое внимание, на наш взгляд, заслуживает ситуация, которая складывается с мобильностью и миграционными намерениями молодежи на Дальнем Востоке России, особой зоне геостратегических интересов страны.

Таким образом, для успешного развития приграничных регионов важно обеспечить транспарентный механизм социальной и трудовой мобильности, основанной на получении качественного образования, только так можно будет обеспечить рост человеческого потенциала и экономики региона, закрепление молодежи на данных территориях. Также необходимо обеспечить рост качества жизни в регионе, так как только таким образом можно повернуть процессы миграции образованной молодежи вспять. Это должно стать стратегической целью всех государственных программ и проектов на Дальнем Востоке, ведь это не просто отдаленные территории, окраина страны, это регион где у России есть экономические и геополитические цели, которых необходимо достичь. 


\section{Литература}

1. Авраамова Е. М. Тенденции занятости российской молодежи в регионах // Сощиологические исследования. 2018. № 9. С. 130-134. DOI: 10.31857/S013216250001969-8

2. Антонова Н.Л. Потенциальная территориальная мобильность молодежи: факторы, барьеры, стратегии // Вестник Удмуртского университета. Социология, политология, международные отношения. 2019. Том 3. №3. С. 277-282.

3. Бёрджесс Э.У. Рост города: Введение в исследовательский проект. // Чикагская социология: Сб. переводов / РАН. ИНИОН. Центр социал. науч.-информ. исслед. Отд. социологии и социал. психологии; Сост. и пер. Николаев В.Г.; Отв. ред. Ефременко Д.В. М., 2015. 430 с.

4. Бурдье П. Социология социального пространства. / пер. с фрранц.; отв.ред. перевода Н.А. Шматков. М.: Институт экспериментальной социологии; СПб.: Алетейя, 2007. 288 с

5. Гидденс Э. Устроенное общество: Очерк теории структурации. М.: Академический проект. 2003. 525 с.

6. Глазырина И.П., Фалейчик Л.М. Восточное приграничье России: проблема сохранения человеческого капитала // ЭКО. 2014. № 11. С. 5-19.

7. Гудков Л. Молоды в стране не хватает воздуха // Независимая газета, 2016 от 01.03.2016. URL: https://www.ng.ru/ng_politics/2016-03-01/9_young.html (дата обращения: 01.09 .2020$)$

8. Евстифеева Е.А., Филиппченкова С.И. Личностное конструирование в практиках мобильности // Вестник ТвГУ. Серия "Философия". 2018. № 4. С. 36-45.

9. Кастельс М. Власть коммуникации. М.: Изд. Дом Высшей школы экономики. 2016. 564 c.

10. Омельченко Е., Сабирова Г., Крупец Я. Социальная мобильность молодежи в фокусе тройной рефлексии // ИНТЕРакция. ИНТЕРвью. ИНТЕРпретация. 2015. № 10 . С. 9-25.

11. Омельченко Е.Л. Молодежный активизм в России и глобальные трансформации его смысла // Журнал исследования социальной политики. 2005. Т.3, № 1. С. 5986.

12. Распоряжение Правительства РФ от 29.11.2014 N 2403-р "Об утверждении Основ государственной молодежной политики Российской Федерации на период до 2025 года" [Электронный ресурс]. URL: https://base.garant.ru/70813498/ (дата обращения: 01.09.2020).

13. Рыбаковский Л.Л. Предыстория возникновения теории трех стадий миграционного процесса // Уровень жизни населения регионов. 2018. № 2. С. 86-94.

14. Сорокин П. А. Человек. Цивилизация. Общество. М.: Политиздат, 1992. 543 с.

15. Турен А. Возвращение человека действующего. Очерк социологии. М.: Научный мир, 1998. 204 с.

16. Урри Дж. Мобильности. М.: Праксис, 2012. 576 с.

17. Федеральный закон от 1 мая 2016 г. № 119-Ф3 "Об особенностях предоставлении гражданам земельных участков, находящихся в государственной или муниципальной собственности и расположенных на территориях субъектов Дальневосточного федерального округа, и о внесение изменений в отдельные законодательные акты Российской Федеращии". [Электронный ресурс]. URL: http://www.consultant.ru/document/ cons_doc_LAW_197427/ (дата обращения: 01.09.2020).

\section{Транслитерация по ГОСТ 7.79-2000 Система Б}

1. Avraamova E. M. Tendentsii zanyatosti rossijskoj molodezhi v regionakh // Sotsiologicheskie issledovaniya. 2018. № 9. S. 130-134. DOI: 10.31857/S013216250001969-8

2. Antonova N.L. Potentsial'naya territorial'naya mobil'nost' molodezhi: faktory, bar'ery, strategii // Vestnik Udmurtskogo universiteta. Sotsiologiya, politologiya, mezhdunarodnye otnosheniya. 2019. Tom 3. № 3. S. 277-282.

3. Byordzhesc EH.U. Rost goroda: Vvedenie v issledovatel'skij proekt. // CHikagskaya sotsiologiya: Sb. perevodov / RAN. INION. TSentr sotsial. nauch.-inform. issled. Otd. sotsiologii i sotsial. psikhologii; Sost. i per. Nikolaev V.G.; Otv. red. Efremenko D.V. M., 2015. $430 \mathrm{~s}$.

4. Burd'e P. Sotsiologiya sotsial'nogo prostranstva. / per. s frants.; otv.red. perevoda N.A. SHmatkov. M.: Institut ehksperimental'noj sotsiologii; SPb.: Aletejya, 2007. 288 s.

5. Giddens EH. Ustroennoe obshhestvo: Ocherk teorii strukturatsii. M.: Akademicheskij proekt. 2003. $525 \mathrm{~s}$.

6. Glazyrina I.P., Falejchik L.M. Vostochnoe prigranich'e Rossii: problema sokhraneniya chelovecheskogo kapitala // EHKO. 2014. № 11. S. 5-19.

7. Gudkov L. Molody v strane ne khvataet vozdukha // Nezavisimaya gazeta, 2016 ot 01.03.2016. URL: https://www.ng.ru/ng_politics/2016-03-01/9_young.html (data obrashheniya: 01.09.2020). 
8. Evstifeeva E.A., Filippchenkova S.I. Lichnostnoe konstruirovanie v praktikakh mobil'nosti // Vestnik TvGU. Seriya "Filosofiya". 2018. № 4. S. 36-45.

564 s.

9. Kastel's M. Vlast' kommunikatsii. M.: Izd. Dom Vysshej shkoly ehkonomiki. 2016.

10. Omel'chenko E. Sabirova G., Krupets YA. Sotsial'nava mobil'nost' molodezhi v fokuse trojnoj refleksii // INTERaktsiya. INTERv'yu. INTERpretatsiya. 2015. № 10. S. 9-25.

11. Omel'chenko E.L. Molodezhnyj aktivizm v Rossii i global'nye transformatsii ego smysla // ZHurnal issledovaniya sotsial'noj politiki. 2005. T. 3, № 1. S. 59-86.

12. Rasporyazhenie Pravitel'stva RF ot 29.11.2014 N 2403-r "Ob utverzhdenii Osnov gosudarstvennoj molodezhnoj politiki Rossijskoj Federatsii na period do 2025 goda" [EHlektronnyj resurs]. URL: https://base.garant.ru/70813498/ (data obrashheniya: 01.09.2020).

13. Rybakovskij L.L. Predystoriya vozniknoveniya teorii trekh stadij migratsionnogo protsessa // Uroven' zhizni naseleniya regionov. 2018. № 2. S. 86-94.

14. Sorokin P. A. CHelovek. TSivilizatsiya. Obshhestvo. M.: Politizdat, 1992. 543 s.

15. Turen A. Vozvrashhenie cheloveka dejstvuyushhego. Ocherk sotsiologii. M.: Nauchnyj mir, 1998. 204 s.

16. Urri Dzh. Mobil'nosti. M.: Praksis, 2012. 576 s.

17. Federal'nyj zakon ot 1 maya 2016 g. № 119-FZ "Ob osobennostyakh predostavlenii grazhdanam zemel'nykh uchastkov, nakhodyashhikhsya v gosudarstvennoj ili munitsipal'noj sobstvennosti i raspolozhennykh na territoriyakh sub"ektov Dal'nevostochnogo federal'nogo okruga, i o vnesenie izmenenij v otdel'nye zakonodatel'nye akty Rossijskoj Federatsii". [EHlektronnyj resurs]. URL: http://www.consultant.ru/document/ cons_doc_ LAW_197427/ (data obrashheniya: 01.09.2020).

Костина Е. Ю., Орлова Н. А. Социальная мобильность в приграничье: взгляд молодежи.

В статье рассмотрена готовность современной студенческой молодежи приграничья к различным формам мобильности, в том числе и к смене места текущего места жительства в поисках возможности для самореализации и удовлетворения своих потребностей на более высоком уровне. На материалах социологического исследования, проведенного авторами в 2020 году, показано, что четверо из пяти молодых людей рассматривают возможность миграции из Приморского края. Сложившаяся тенденция приводит к обнищанию человеческого капитала Дальнего Востока России, лишая данную территорию возможности развивать инновационную әкономику и обеспечивать высокий уровень качества жизни местному населению.

Ключевые слова: социальная мобильность, трудовая мобильность, миграиия, модернизация, практики мобильности, студенческая молодежь, модели поведения

\section{Kostina E. Yu., Orlova N. A. Social mobility in the borderlands: the view of young people.}

The article looks at the readiness of modern borderline students for various forms of mobility, including changing their current place of residence in search of opportunities for self-realisation and satisfaction of their needs at a higher level. A sociological study conducted by the authors in 2020 shows that four out of five young people are considering migration from the Primorsky Region. This trend is impoverishing human capital in Russia's Far East, depriving the area of the opportunity to develop an innovative economy and ensure a high quality of life for the local population.

Key words: social mobility, labor mobility, migration, modernization, mobility practices, student youth, behavior patterns

Для цитирования: Костина Е. Ю., Орлова Н. А. Социальная мобильность в приграничье: взгляд молодежи // Ойкумена. Регионоведческие исследования. 2020. № 4. С. 16-22. DOI: $10.24866 / 1998-6785 / 2020-4 / 16-22$

For citation: Kostina E. Yu., Orlova N. A. Social mobility in the borderlands: the view of young people // Ojkumena. Regional researches. 2020. № 4. P. 16-22. DOI: 10.24866/19986785/2020-4/16-22 